\title{
Resistance to Arteriosclerosis in Pigs with von Willebrand's Disease
}

\author{
SPONTANEOUS AND HIGH CHOLESTEROL DIET-INDUCED
}

ARTERIOSCLEROSIS

\author{
Valentin Fuster, E. J. Walter Bowie, Jon C. Lewis, David N. Fass, \\ Charles A. Owen, Jr., and ARnold L. Brown, Mayo Clinic and Mayo \\ Foundation, Rochester, Minnesota 55901
}

\begin{abstract}
A B S T RACT The aortas of 11 pigs (aged 1-3 yr) with homozygous von Willebrand's disease $(\mathrm{vWd})$ were compared with those of 11 normal pigs of the same ages. Six of the controls exhibited multiple arteriosclerotic plaques with intimal thickening of 63$130 \mu \mathrm{m}$. In contrast, none of the pigs with $\mathrm{vWd}$ had multiple plaques, and only one had a lesion $>2 \mathrm{~mm}$ in diameter.

In a subsequent study, 3-mo-old pigs (11 controls and 7 with homozygous $v \mathrm{Wd}$ ) were placed on a $2 \%$ cholesterol diet for up to $6 \mathrm{mo}$. All of the controls developed arteriosclerotic plaques in the aorta, and in nine of the controls, at least $13 \%$ of the entire surface was involved. Intimal thickness ranged up to 390 $\mu \mathrm{m}$. In contrast, four of the pigs with $\mathrm{vWd}$ did not develop such lesions, two developed arteriosclerotic lesions affecting 6 and $7 \%$ of the aortic surface, and the seventh had $13 \%$ of the aortic surface involved.

Most of the pigs with $\mathrm{vWd}$, however, developed flat fatty lesions in contrast to the normal pigs whether on the normal or the high cholesterol diet. There was blue staining of the flat fatty lesions when two pigs with vWd were injected with Evans blue dye antemortem. By electron microscopy, severe endothelial damage was apparent, but there was no intimal proliferation. The coincidence of the impaired platelet-arterial wall interaction and lack of arteriosclerosis in this bleeding disease is discussed.
\end{abstract}

\section{INTRODUCTION}

For several years we have maintained a colony of pigs with von Willebrand's disease. These animals share all the usually observed hemostatic abnormalities of the

Received for publication 11 April 1977 and in revised form 2 September 1977. severe form of the disease in humans (1). It was incidentally observed, when these pigs died from bleeding, that there was negligible aortic arteriosclerosis. This was unexpected, for pigs, whose arterial system closely resembles that of man (2), often develop arteriosclerotic lesions early in life (3). In man and pigs the lesions are similar in distribution and development $(2,4)$.

This study was thus begun, first to compare spontaneous arteriosclerosis in normal and bleeder swine, and second to administer a high cholesterol diet to the pigs to see whether arteriosclerosis could be forced. Normal pigs develop arteriosclerotic lesions resembling those of the human disease when these animals are given a diet high in cholesterol for as little as 6 mo (5-7).

\section{METHODS}

Swine. The original Poland-China pigs with $\mathrm{vWd}^{1}$ were crossed with Yorkshire-Hampshire pigs to establish our present colony. Our control pigs were also a mixture of Poland-China and Yorkshire-Hampshire. The aortas of 11 pigs with homozygous vWd, 7 male and 4 female, were studied. These were bred and raised at Mayo Institute Hills Farm. All had died of nasal or gastrointestinal bleeding between January 1970 and December 1974. At the time of death the pigs were 1-3-yr old (mean $1.6 \mathrm{yr}$ ), they weighed an average of $150 \mathrm{~kg}( \pm 85 \mathrm{SD})$, and the average heart weight was $663 \mathrm{~g}( \pm 211 \mathrm{SD})$. 11 control pigs, all male, were obtained from a slaughterhouse in August 1974 . They were $\cong 1-3$-yr old. Their body weights averaged $216 \mathrm{~kg}( \pm 61 \mathrm{SD})$, and heart weights averaged $641 \mathrm{~g}( \pm 228$ $\mathrm{SD})$. Heart weight was not significantly different in the controls and with animals vWd; body weight was higher in the control animals $(P=0.05$, rank sum test). There was no evi-

${ }^{1}$ Abbreviation used in this paper: vWd, von Willebrand's disease. 
dence of visceral or infectious disease in any of the controls or pigs with $v W d$.

18 additional pigs were subjected to an atherogenic, high cholesterol diet for $6 \mathrm{mo}$, beginning at the age of $3 \mathrm{mo}$. 11 were normal control pigs, 5 male and 6 female, and 7 suffered from homozygous vWd, 4 male and 3 female. All were housed at Mayo Institute Hills Farm and were fed the same diet concurrently. Two pigs bled to death at 3 and 4 mo, and in each instance a control animal was killed. At autopsy, mean body weights were $105 \mathrm{~kg}( \pm 30 \mathrm{SD})$ for the controls and $94 \mathrm{~kg}( \pm 21 \mathrm{SD})$ for the pigs with vWd. Mean heart weights were $300 \mathrm{~g}( \pm 76 \mathrm{SD})$ for controls and $270 \mathrm{~g}$ $( \pm 59$ SD) for animals with $v W d$. Both body and heart weights were not significantly different (rank sum test) in the controls and animals with vWd.

Diets (Table I). The 11 pigs with $\mathrm{vWd}$ in the spontaneous atherosclerosis group received a mixed, ground meal, $\cong 50() \mathrm{g} / 40 \mathrm{~kg}$ body wt. The diet of the 11 control animals is unknown since they were raised on farms not under our supervision.

The controls and pigs with $\mathrm{vWd}$ receiving the atherogenic diet also were fed $\cong 500 \mathrm{~g} / 40 \mathrm{~kg}$ body wt. The diet contained cholesterol 2\%, tallow 20\%, and hog bile extract $1 \%$.

Laboratory data during life. Platelet counts (8) averaged $329,700 / \mu \mathrm{l}( \pm 104,900 \mathrm{SD})$ in control swine and $375,800 / \mu \mathrm{l}( \pm 161,200 \mathrm{SD})$ in pigs with $\mathrm{vWd}$. The partial thromboplastin time (8) averaged $26 \mathrm{~s}( \pm 3 \mathrm{SD})$ in controls and $3.3 \mathrm{~s}( \pm 4 \mathrm{SD})$ in animals with $\mathrm{vWd}$. Bleeding times, by the Mertz ear saline immersion method (9), averaged $31 / 2 \mathrm{~min}( \pm 2 \mathrm{SD})$ in controls and were all $>15 \mathrm{~min}$ in pigs with $v W d$. In the colony from which these pigs were selected, Factor VIII coagulant activity (8) averaged 17\% ( \pm 8 SD) of control values. von Willebrand antigen was measured

\section{TABLE I}

Experimental Diets

\begin{tabular}{lcc}
\hline \multicolumn{1}{c}{ Diet components } & $\begin{array}{c}\text { Spontaneous } \\
\text { arteriosclerosis } \\
\text { study }\end{array}$ & $\begin{array}{c}\text { High cholesterol } \\
\text { diet-induced } \\
\text { arteriosclerosis } \\
\text { study }\end{array}$ \\
\hline Mixg feed & g/kg feed \\
Soybean oil meal & 772 & 532 \\
Meat scraps & 135 & 190 \\
Dextrose & 50 & - \\
Cholesterol & - & 10 \\
Tallow & - & 20 \\
Hog bile extract (hog gall, 75\% & - & 200 \\
$\quad$ solids) & - & 10 \\
Salt, iodized & 5 & 5 \\
Dicalcium phosphate & 24 & 24 \\
Vitamins* trace minerals $\$$ and & & 9 \\
$\quad$ antibiotics & 14 & 5 \\
\hline
\end{tabular}

* Vitamins in both diets included choline, thiamine, pantothenate, riboflaven, niacin, pyridoxine, folacin, $\mathrm{B}_{12}, \mathrm{~K}, \mathrm{~A}$, $\mathrm{D}_{3}$, and $\mathrm{E}$.

$\$$ Trace elements in the practical diets included $\mathrm{Zn}, \mathrm{Fe}, \mathrm{Mn}$, I, and Co.

\$ The antibiotic Anero SP250 (Allird Mills, Inc., Waynes Division, Chicago, Ill.), which contains chlortetracycline, sulfamethazine, and penicillin, was given. by a local adaptation (10) of the quantitative immunoelectrophoretic method of Laurell (11) and Zimmerman et al. (12). All the pigs with vWd had a plasma concentration $<3 \%$ of control. The ristocetin-von Willebrand factor was measured by Olson's (10) modification of the method of Weiss et al. (13) and was completely absent in all the pigs with vWd; dilutions of normal plasma down to $3.0 \%$ can be detected by this assay.

Serum cholesterol (14) preceding the high cholesterol diet period, was higher in the controls when compared with animals with vWd $(P<0.02)$; this was apparent in the low density lipoprotein fraction (15) (Table II). When both groups were fed the high cholesterol diet, serum cholesterol increased about fivefold (Table II) and the levels were not significantly different between both groups; it is worth mentioning that one of the control pigs had serum cholesterol and lipoprotein levels that were about two- to threefold higher than in the other controls and pigs with $\mathrm{vWd}$. Serum triglycerides (16) and the corresponding lipoprotein fractions (17) were about the same in the controls and pigs with $\mathrm{vWd}$, before the high cholesterol diet period and when the pigs were fed this atherogenic diet. In both controls and pigs with $\mathrm{vWd}, \cong 70 \%$ of the cholesterol was in the low density lipoproteins and $70 \%$ of the triglycerides was in the very low density fraction.

Postmortem analysis. The entire aorta from aortic valve to the abdominal bifurcation was removed and preserved in $10 \%$ formalin. All 22 aortas from the pigs in the spontaneous arteriosclerosis study were analyzed at the same time. The same was true for the 18 pig aortas from the atherogenic diet group. In all of the aortas, identification and quantitation of raised arteriosclerotic plaques and flat fatty lesions were performed by gross and microscopic examination.

Gross examination: arteriosclerotic plaques. The aortas, opened longitudinally, were carefully inspected for lesions. Two types of plaques were seen (18). One was a raised fatty plaque consisting of a soft, yellow elevation with predominantly fat-staining material as detected microscopically. The other was a fibrous plaque consisting of a firm, gray, very prominent elevation with predominantly collagen and elastic bundles as detected microscopically. Quantita-

TABLE II

High Cholesterol Diet-Induced Arteriosclerosis Study: Average Serum Cholesterol and Serum Triglycerides

\begin{tabular}{|c|c|c|c|c|}
\hline \multirow[b]{2}{*}{ Serum lipids* } & \multicolumn{2}{|c|}{$\begin{array}{c}\text { Predietary } \\
\text { period }\end{array}$} & \multicolumn{2}{|c|}{ Dietary period } \\
\hline & Normal & $v W d$ & Normal & $v W d$ \\
\hline & & & & \\
\hline \multicolumn{5}{|l|}{ Cholesterol } \\
\hline Serum & 109 & 88 & 600 & 474 \\
\hline VLDL & 6 & 7 & 41 & 17 \\
\hline LDL & 69 & 48 & 495 & 398 \\
\hline HDL & 34 & 33 & 64 & 59 \\
\hline \multicolumn{5}{|l|}{ Triglycerides } \\
\hline Serum & 50 & 46 & 66 & 53 \\
\hline VLDL & 30 & 31 & 39 & 38 \\
\hline LDL & 11 & 7 & 8 & 8 \\
\hline HDL & 9 & 8 & 19 & 7 \\
\hline
\end{tabular}

* VLDL, very low density lipoprotein; LDL, low density lipoprotein; HDL, high density lipoprotein. 
tion of plaques was carried out in the following manner. In the spontaneous arteriosclerosis study, since the plaques were multiple and small, the number of plaques and the longest diameter in each of the plaques were recorded. In the atherogenic-diet study, plaques were located in the aortic arch or bifurcation of the aorta (or both). Since they were very extensive, quantitation was done by recording the proportion of the aortic area affected. The proportion of the area affected was measured by cutting it out from a drawing of the aorta and weighing the transparent acetate paper.

Gross examination: fatty lesions. After at least $48 \mathrm{~h}$ of fixation in formalin, the aortas were stained with Sudan IV by the method of Holman et al. (19). Two types of lesions became visible - one a flat fatty lesion and the other, raised plaques (20). In the first type, the stained lesions were not elevated and did not coincide with the raised arteriosclerotic plaques. The proportion of the aortic area involved by these flat fatty lesions was quantitated. In the other type, in which the plaques were raised, the stain did coincide with the arteriosclerotic plaques seen before staining. The raised fatty plaques were homogeneously stained whereas the fibrous plaques were stained more prominently in the periphery.

Microscopic examination. A full-thickness segment, $\cong 5$ $\mathrm{mm}^{2}$ in surface area, was excised from each arteriosclerotic plaque and each flat fatty lesion. An apparently normal segment was excised near each lesion but on the opposite side, to serve as a control. The tissues were cut as accurately as possible perpendicular to the surface. They were stained with hematoxylin and eosin, with Heidenhain's Weigert-Van Gieson's stain, and with Sudan IV. Histologic sections were photographed at a magnification of $\times 160-400$. From these pictures, the thickness of the intima from the surface down to the internal elastic membrane was measured.

Measurement of endothelial permeability and damage. Evans blue dye, $0.5 \%$ solution (wt/vol) in saline, was filtered through the $0.2-\mu \mathrm{m}$ filter and injected through a cannula into the external jugular vein of four of the pigs on the atherogenic diet (two control and two vWd). $3 \mathrm{~h}$ later they were anesthetized with intravenous pentobarbital in a dose of $20 \mathrm{mg} / \mathrm{kg}$ body wt. After the abdomen and thorax had been opened, a cannula was placed in the aortic arch and another cannula in a femoral artery. $3 \%$ glutaraldehyde, pH 7.2 in $0.1 \mathrm{M}$ phosphate buffer, was perfused into the aortic arch for $25 \mathrm{~min}$ under a hydrostatic pressure of 85 $\mathrm{mm} \mathrm{Hg}$. The perfusate emerged from the femoral artery. The aortas were then excised from the aortic valve ring to the abdominal bifurcation and carefully removed intact. After rinsing with Puck's saline-G (Grand Island Biological Co., Grand Island, N. Y.), each aorta was opened longitudinally along its ventral surface. It was washed gently with saline, and adventitital debris was stripped off. The proportion of the aortic surface involved by these blue-stained areas was quantitated.

Full-thickness segments, $1 \mathrm{~cm}^{2}$ in surface area, were excised from the blue zones and adjacent unstained areas. Each segment was divided in three. One portion was fixed in $1 \% \mathrm{OsO}_{4}$, dehydrated through a series of ethanol solutions, and dried from $\mathrm{CO}_{2}$ by the critical-point method (21). The dried tissue was coated with $100 \AA$ of gold-palladium and carbön, examined by scanning electron microscopy, and photographed. Particular attention was directed at changes in arterial endothelium. The second portion, also fixed in $1 \% \mathrm{OsO}_{4}$, was stained en bloc with $2 \%$ aqueous uranyl acetate, ethanol dehydrated, and embedded in Epon 812. Sections were examined by transmission electron microscopy and photographed. The third portion was fixed in $10 \%$ formalin and sections were stained with hematoxylin and eosin, Heidenhain's Weigert-Van Gieson's stain, and Sudan IV.

\section{RESULTS}

Spontaneous arteriosclerosis (Table III). 6 of the 11 control pigs had multiple arteriosclerotic raised fatty plaques, and 1 pig showed a single plaque of $>2 \mathrm{~mm}$ in diameter. The larger, multiple plaques were found exclusively in the heavier pigs. Intimal thickening over the plaques was $63-130 \mu \mathrm{m}$ and in the neighboring normal areas, 20-64 $\mu \mathrm{m}$ (Fig. 1A, B). None of the pigs with vWd had multiple plaques. Four had single plaques, but only one plaque was $>2 \mathrm{~mm}$ in diameter. This decreased incidence and extent of arteriosclerotic plaques in the pigs with $\mathrm{vWd}$ when compared with the controls was significant $(P<0.01$, rank sum test). Intimal thickening over the few plaques found in the pigs with vWd was $50-123 \mu \mathrm{m}$, about the same as in the controls, and 19-48 $\mu \mathrm{m}$ in the neighboring normal areas.

Although the presence of arteriosclerotic plaques characterized the controls, an equally striking lesion characterized the pigs with $\mathrm{vWd}$. This was the flat fatty lesion (Fig. 2A). 7 of the 11 aortas from pigs with vWd had such lesions but only one of the controls.

TABLE III

Spontaneous Development of Arteriosclerotic Plaques and Flat Fatty Lesions

\begin{tabular}{|c|c|c|c|c|c|c|}
\hline \multirow[b]{2}{*}{ Pig no. } & \multirow[b]{2}{*}{ Sex } & \multirow[b]{2}{*}{ Age } & \multirow[b]{2}{*}{$w_{t}$} & \multicolumn{2}{|c|}{$\begin{array}{l}\text { Number of } \\
\text { arteriosclerotic } \\
\text { placques }\end{array}$} & \multirow{2}{*}{$\begin{array}{l}\text { Flat fatty } \\
\text { lesions, } \\
\% \text { of aortic } \\
\text { surface }\end{array}$} \\
\hline & & & & $<2 \mathrm{~mm}$ & $>2 \mathrm{~mm}$ & \\
\hline & & mo & $\mathrm{kg}$ & & & \\
\hline \multicolumn{7}{|c|}{ Control pigs } \\
\hline 1 & $\mathbf{M}$ & & 318 & 7 & 2 & () \\
\hline 2 & $\mathbf{M}$ & & 295 & () & 7 & () \\
\hline 3 & $\mathbf{M}$ & & 261 & () & () & () \\
\hline 4 & $\mathbf{M}$ & & 250 & 5 & () & () \\
\hline 5 & M & & 239 & () & () & () \\
\hline 6 & $\mathbf{M}$ & & 193 & 3 & () & () \\
\hline 7 & $\mathbf{M}$ & & 193 & 3 & 0 & () \\
\hline 8 & $M$ & & 182 & () & () & 0 \\
\hline 9 & M & & 170 & () & () & () \\
\hline 10 & M & & 141 & 6 & 1 & 5 \\
\hline 11 & $\mathbf{M}$ & & 136 & () & 1 & () \\
\hline \multicolumn{7}{|c|}{ Pigs with vWd } \\
\hline 1 & $\mathbf{M}$ & 44 & 318 & () & () & 10 \\
\hline 2 & $\mathbf{M}$ & 33 & 227 & 1 & () & 30 \\
\hline 3 & $\mathbf{M}$ & 22 & 227 & () & () & 20 \\
\hline 4 & $\mathbf{M}$ & 20 & - & 1 & 0 & 5 \\
\hline 5 & $\mathrm{~F}$ & 18 & 105 & () & () & 10 \\
\hline 6 & $F$ & 16 & - & 1 & () & () \\
\hline 7 & $\mathrm{~F}$ & 15 & 110 & () & 0 & 5 \\
\hline 8 & $\mathbf{M}$ & 14 & 95 & () & 1 & 5 \\
\hline 9 & $\mathbf{M}$ & 14 & 95 & () & () & () \\
\hline 10 & $\mathrm{~F}$ & 12 & 91 & () & 0 & 0 \\
\hline 11 & $\mathbf{M}$ & 12 & 91 & () & 0 & 0 \\
\hline
\end{tabular}


These nonproliferative, nonarteriosclerotic lesions showed, by light microscopy, subendothelial infiltrations of fat (Fig. 2B), without significant thickening
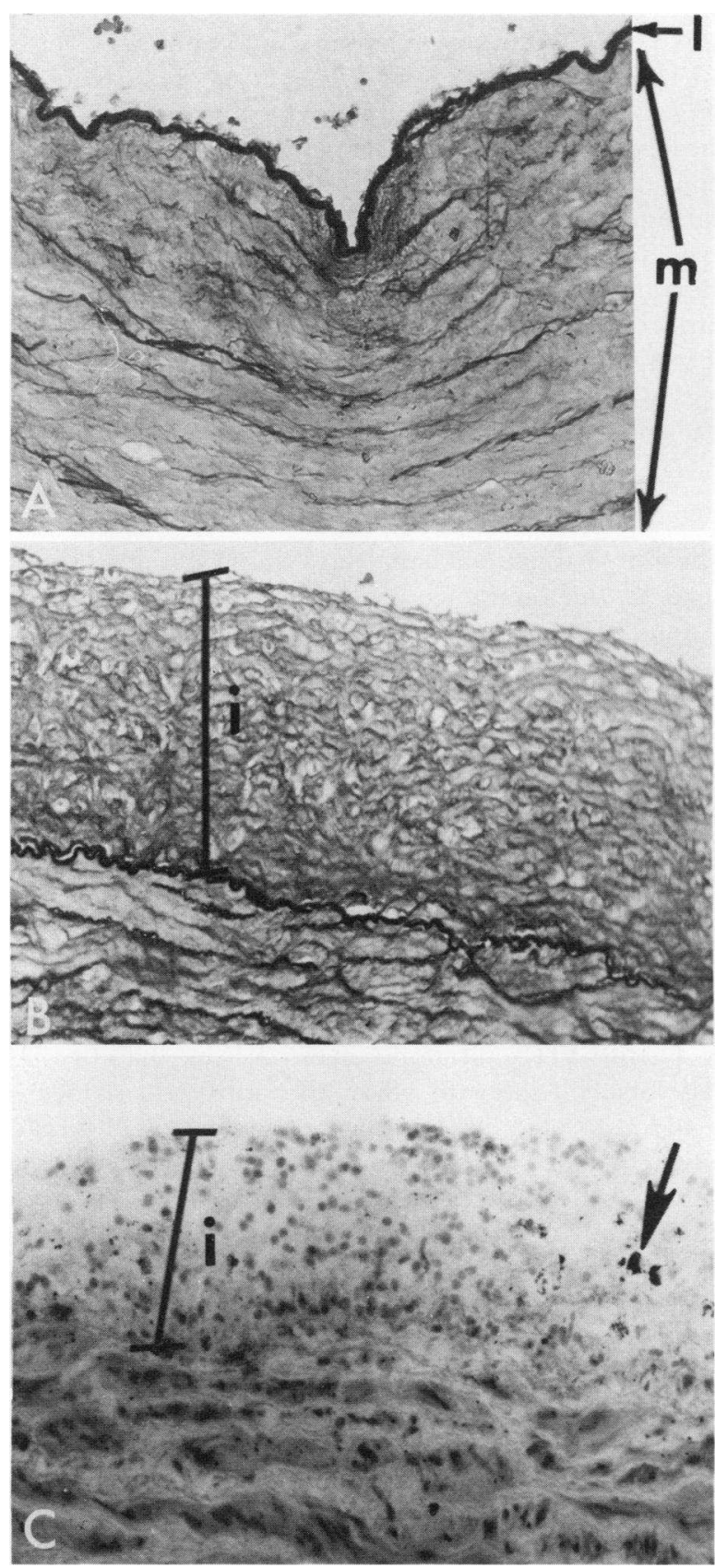

Figure 1 (A) Light micrograph of normal section of distal aorta of control animal. Thin intima is demarcated by internal elastic lamina ( $l$ ). Endothelial cells are barely visible. Media $(m)$ is clearly visible. $(\times 160)$ (B) Early arteriosclerotic plaque of control animal. Intima ( $i$ ) occupies more than half of this micrograph and demonstrates pronounced increase in thickness. $(\times 160)(C)$ In the intima $(i)$ lipid-laden cells (arrow) are present in an arteriosclerotic plaque of control animal. $(\times 250$.)
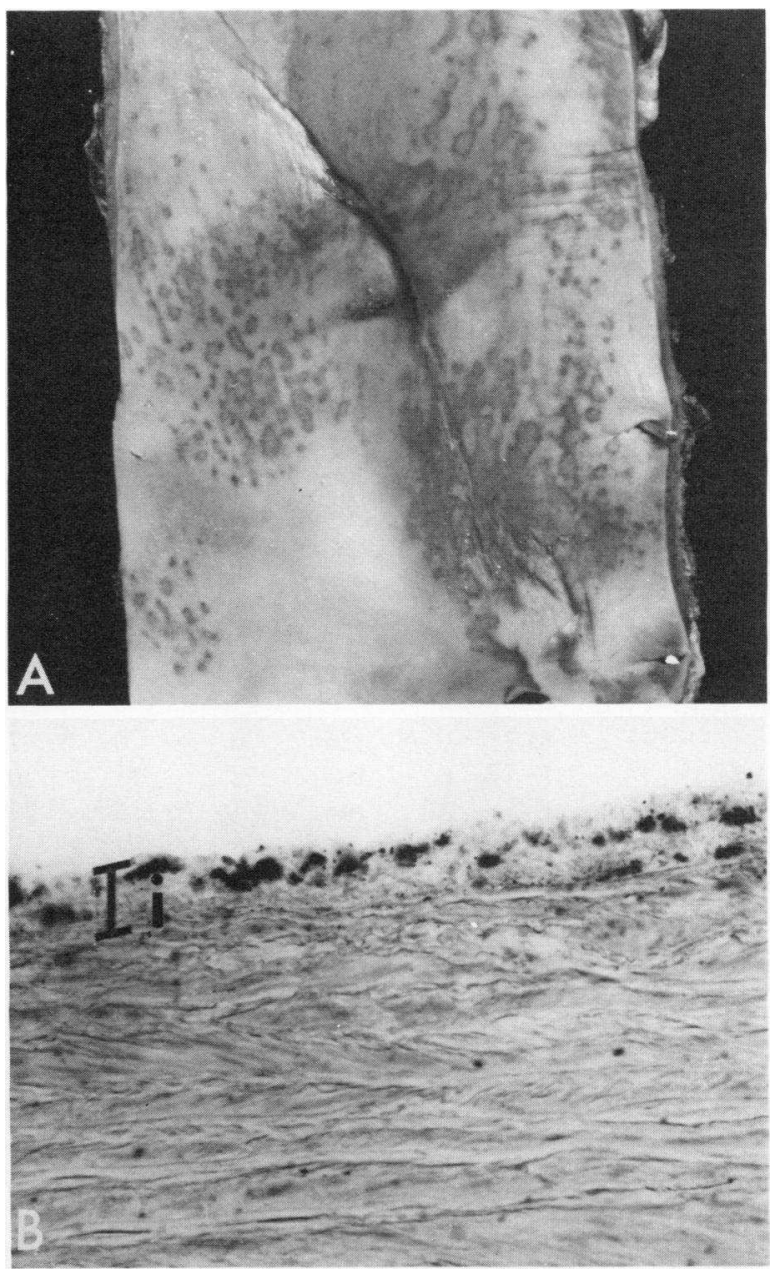

Figure 2 (A) Fatty, stained, grossly normal aorta from pig with vWd. (B) Light microscopy of fatty, stained, grossly normal aorta from pig with $\mathrm{vWd}$, showing subendothelial infiltration without significant proliferation of intima $(i)$. $(\times 400$.)

of the intima, which measured 27-81 $\mu \mathrm{m}$. The arteriosclerotic raised fatty plaques all stained with Sudan IV (Fig. 1C).

Induced arteriosclerosis (Table IV). All of the 11 controls on the high cholesterol diet developed raised fatty arteriosclerotic plaques, and 10 of the pigs developed raised fibrous arteriosclerotic plaques. In nine of the pigs the aortic arteriosclerotic plaques exceeded $12 \%$ of the entire surface. The plaques involved the arch of the aorta or the bifurcation of the abdominal aorta, or both. Unlike the small, discrete plaques in the pigs with spontaneous arteriosclerosis, these tended to be large, irregular, elongated plaques, often only one in each characteristic area of the aorta. Intimal thickening over the plaques was $5(0-390 \mu \mathrm{m}$ (neighboring normal areas, $8-40 \mu \mathrm{m}$ ).

Only three of the seven pigs with $\mathrm{vWd}$ developed 
TABLE IV

Induced Arterial Lesions

\begin{tabular}{ccrrrrr}
\hline Pig no. & Sex & $\begin{array}{c}\text { Months } \\
\text { on } \\
\text { diet }\end{array}$ & Wt & $\begin{array}{c}\text { Raised } \\
\text { fibrous } \\
\text { plaques }\end{array}$ & $\begin{array}{r}\text { Raised } \\
\text { fatty } \\
\text { plaques }\end{array}$ & $\begin{array}{r}\text { Flat } \\
\text { fatty } \\
\text { lesion }\end{array}$ \\
Control pigs & & & $k g$ & $\%$ & $\%$ & $\%$ \\
1 & F & 6 & 155 & 5 & 12 & 0 \\
2 & F & 6 & 155 & 0 & 2 & 1 \\
3 & F & 6 & 145 & 4 & 10 & 0 \\
4 & F & 6 & 99 & 6 & 28 & 0 \\
5 & F & 6 & 97 & 4 & 11 & 0 \\
6 & F & 6 & 96 & 10 & 9 & 0 \\
7 & M & 6 & 86 & 10 & 17 & 0 \\
8 & M & 4 & 86 & 18 & 18 & 0 \\
9 & M & 3 & 86 & 4 & 11 & 20 \\
10 & M & 6 & 84 & 3 & 10 & 2 \\
11 & M & 6 & 74 & 3 & 2 & 2 \\
Pigs with vWd & & & & & & \\
1 & M & 6 & 125 & 0 & 0 & 7 \\
2 & F & 6 & 105 & 2 & 11 & 0 \\
3 & F & 6 & 1144 & 1 & 5 & 23 \\
4 & M & 6 & 95 & 0 & 7 & 7 \\
5 & F & 6 & 91 & 0 & 0 & 20 \\
6 & M & 4 & 82 & 0 & 0 & 2 \\
7 & M & 3 & 57 & 0 & 0 & 2 \\
\hline & & & & & & \\
\hline
\end{tabular}

raised fatty lesions or fibrous arteriosclerotic plaques. Moreover, the plaques were all discrete; thus, in two of these three pigs the plaques did not exceed $7 \%$ of the aortic surface. This decreased incidence and extension of arteriosclerotic plaques in the pigs with $v W d$ when compared with the controls was significant $(P<0.01$, rank sum test $)$. Intimal thickening over the few plaques found in the pigs with $\mathrm{vWd}$ was about the same as in the controls, 35-525 $\mu \mathrm{m}$ (neighboring normal areas $8-42 \mu \mathrm{m}$ ).

Despite the low incidence and extent of arteriosclerotic plaques, the aortas from pigs with $\mathrm{vWd}$ showed flat fatty lesions. The aortas of six pigs were involved, the areas of the lesions ranging from 2 to $23 \%$ of the total aortic surface area. As in spontaneous arteriosclerosis study, these nonarteriosclerotic lesions were characterized, on light microscopy, by subendothelial infiltration of fat without intimal thickening $(12-50 \mu \mathrm{m})$.

Evans blue staining and electron microscopy. When pigs were given Evans blue intravenously $3 \mathrm{~h}$ before death, normal areas of aorta were unstained, certain zones were pale blue, and smaller areas were intensely blue. The pattern of Evans blue staining in the two cholesterol-fed normals and two cholesterol-fed pigs with $v W d$ was distinctly different from that obtained with normal pigs on a normal diet. In these latter animals of comparable age, the Evans blue staining was localized to the aortic arch and ostia of the intercostal arteries. ${ }^{2}$ In animals on a high cholesterol diet, diffuse Evans blue staining with intensely blue areas associated with fatty lesions was found. The intensely blue-stained areas corresponded precisely with the flat fatty lesions typical of the pigs with $\mathrm{vWd}$ and were shown by scanning electron microscopy to be completely denuded of endothelium (Fig. 3A, B). Endothelium in the unstained areas of these same pigs was intact (Fig. 3C, D). Similar correlations between Evans blue staining and endothelial damage were noted in aortas from normal pigs; however, in the normal pigs maintained on a cholesterol diet a significantly smaller percentage of the aortic surface showed intense staining with Evans blue. It was found that an average of $8 \%$ of the aortas from pigs with $\mathrm{vWd}$ had taken up the stain, whereas only $2 \%$ was comparably stained in the normal pigs.

\section{DISCUSSION}

These investigations have shown a pronounced difference in the incidence and extent of arteriosclerotic lesions between normals and pigs with $\mathrm{vWd}$ whether they were on a normal or a high cholesterol diet. An explanation for these results may lie in the unique nature of the bleeding disorder itself; that is, the hemostatic defect in the pigs with $\mathrm{vWd}$ may have protected them from spontaneous or induced arteriosclerosis.

The identified defects in pigs with $\mathrm{vWd}$, and their human counterparts include $(1,22)$ a long bleeding time despite a normal platelet count, reduced retention of platelets in a column filled with glass beads, a deficiency of Factor VIII coagulant activity, a lack of Factor VIII antigenic material, an inability for platelets to aggregate when the antibiotic ristocetin is added to platelet-rich plasma, and a lack of a ristocetin cofactor (von Willebrand factor) in the plasma. Although these attributes of $\mathrm{vWd}$ have not been correlated into a unified, fully satisfactory hypothesis, the consensus is something as follows: The ristocetin cofactor in plasma (von Willebrand factor) is closely allied with, or identical to, antigenic Factor VIII (3). This protein is created by normal endothelial cells and seems to be important in the normal interaction between platelets and damaged endothelial cells $(23,24)$. When the von Willebrand factor is lacking, few platelets are retained in glass bead columns (25) and platelets adhere poorly to subendothelial tissue (26), and as a result the bleeding time after a puncture wound is prolonged (27).

\footnotetext{
${ }^{2}$ Fuster, V., J. C. Lewis, and E. J. W. Bowie. 1978. Aortic Evans blue uptake in vivo and scanning electron microscopy in the evaluation of endothelial integrity of normal and von Willebrand pigs. Manuscript in preparation.
} 
The necessary bonding between platelets and damaged vessels to staunch bleeding may furnish a new clue to the origin of arteriosclerosis. In experimental arteriosclerosis induced by removing the endothelium, platelets initially adhere to denuded subendothelial tissue and undergo intracytoplasmic degranulation. This is followed by intimal migration and proliferation of smooth muscle cells (28). Actually, platelets are believed to release a mitogenic factor that stimulates proliferation of smooth muscle cells; and in fact, smooth muscle cells cannot grow in tissue culture when the serum is derived from platelet-free plasma. Serum from clotted platelet-rich plasma supports cell growth effectively (29). Further support for the role of platelets in the development of arteriosclerosis is given by the experiments of Harker et al. (30) These workers observed that in experimental homocystinemia, platelet consumption correlated well with formation of intimal lesions and arteriosclerosis; and a platelet inhibitor, dipyridamole, prevented the exaggerated platelet consumption. Similarly, Burns et al. (31) prevented formation of balloon catheter-induced intimal lesions in rabbits by using dipyridamole. Moore et al. (32) further found that induced thrombocytopenia prevented the chronic catheter-induced arteriosclerosis in animals. Thrombocytopenia from administration of ${ }^{32} \mathrm{P}$ was found by Cohen and McCombs (33) to prevent arteriosclerosis in rabbits fed an egg yolk diet whereas increased arteriosclerosis accompanied experimental thrombocytosis (34).

In the light of these findings, we will now consider the situation in pigs with vWd. If the platelets cannot effectively adhere to subendothelial surfaces $(24,26)$, the animals are functionally "thrombocytopenic". Further, if such adherence is a necessary first step in the generation of arteriosclerosis (28-30), the animals' life-threatening hemostatic defect may be a lifepreserving vascular phenomenon. Our results indeed suggest that pigs with $\mathrm{vWd}$ are resistant to the development of spontaneous arteriosclerosis and of arteriosclerosis induced by a high cholesterol diet. These animals, however, are prone to develop nonproliferative, nonarteriosclerotic intimal fat infiltration with extensive alterations to overlying endothelium as evidenced by uptake of Evans blue dye and by scanning electron microscopy.

Our observations ${ }^{2}$ on the location of Evans blue staining in aortas from normal pigs maintained on a normal diet is consistent with the study of Somer et al. (35). However, the pattern of Evans blue staining obtained in our studies with cholesterol feeding was more extensive, particularly in the aortas from pigs with $\mathrm{vWd}$ where it coincided with the location of the flat fatty lesions. This finding suggests that cholesterol feeding significantly alters aortic permeability in both normals and pigs with $\mathrm{vWd}$. The precise nature of the alteration in permeability remains to be determined, but the correlation we have noted between uptake of Evans blue dye and endothelial cell damage suggests a direct effect of cholesterol at the endothelial cell level. This suggestion is consistent with observations in cholesterol-fed animals made by other investigators $(6,36-38)$. Davies et al. (39) have recently presented evidence that damage to arterial endothelium overlying fatty lesions may occur during specimen preparation and alcohol dehydration. Such alterations include a disruption in the typically confluent cellular pattern through the appearance of surface tears and disruptions in cell outline. Most of the irregularities described by Davies et al. (39) were focal in nature and differed, ultrastructurally, from those reported here and in previous reports $(38,40)$.

We can offer a speculative explanation for all of these findings. In normal pigs, endothelial injury presumably due to hemodynamic and rheologic factors $(41-44,35)$ and also that induced by a high cholesterol diet $(6,36-38)$ might attract platelets to adhere to the arterial surface. As suggested by several investigators $(28-30,45)$, the platelets may then promote the development of the intimal hyperplasia seen in the early arteriosclerotic plaques. In addition, the adherence of the platelet to the arterial surface in the normal animal may help to repair the endothelium and reduce its permeability (46-49). But in the pig with $\mathrm{vWd}$, intimal hyperplasia or arteriosclerotic plaques would not develop, because the platelet does not adhere (50). In addition, because of the lack of platelet-arterial wall interaction, endothelial integrity might not be restored and permeability might be increased, and this would allow the fat to accumulate in the intima.

It is important to recognize that there may be other explanations for the arteriosclerosis-sparing phenomenon described in the pig with $\mathrm{vWd}$. In the retrospective spontaneous arteriosclerosis study, the body weight was higher in the controls than in the pigs with vWd. This might be due to some differences in the diet, since the control animals were raised on farms not under our supervision; accordingly, a dietcontrolled prospective study of spontaneous arteriosclerosis is now in progress. We doubt, however, that the arteriosclerosis-sparing phenomena in pigs with $\mathrm{vWd}$ is due to differences in body weight, since in the diet-induced arteriosclerosis study the body weight was similar between the control and the animals with vWd.

Another factor that must be considered is the serum cholesterol, because the level preceding the dietinduced arteriosclerosis study was higher in the control pigs than in the pigs with vWd. During the high cholesterol diet, however, the serum cholesterol levels were not statistically different in the two groups of 
animals. Moreover, there was no statistical correlation between the cholesterol level and the incidence and extension of arteriosclerosis; thus, the control pig with the highest cholesterol level had less extensive arteriosclerotic disease. Blood sugar and blood hematocrit were also tested in both groups of animals and were not significantly different. Blood pressure was not recorded because for accurate readings in pigs, arterial cannulation is necessary and this would endanger our bleeder animals.

Lastly, we have considered the possibility that the aortas of the pigs with $\mathrm{vWd}$ are genetically less responsive to the induction of arteriosclerosis than are aortas from normal pigs; thus, we have initiated a series of aortic cross-transplantation studies between the normals and the animals with $\mathrm{vWd}$ to investigate this explanation of our findings.

Little information is available as to the incidence of arteriosclerosis in human vWd. Silwer et al. (51) investigated three cases at autopsy and found atherosclerosis in all three. In one case the bleeding diathesis was mild and the patient had been severely hypertensive for $10 \mathrm{yr}$. In the second, no coagulation data were furnished. In the third, the patient exhibited only minute arterial yellow deposits. Since patients with mild vWd have some von Willebrand factor in their plasma, their situation probably cannot be compared with the homozygous porcine disease in which no von Willebrand factor can be detected at all.

\section{ACKNOWLEDGMENTS}

We greatly appreciate the valuable help of Dr. Lila R. Elveback (Dept. of Medical Statistics and Epidemiology), Dr. Paul E. Zollman (Director of Veterinary Medicine at Mayo Institute Hills Farm), and Dr. Ralph D. Ellefson (Dept. of Lipid Chemistry). We would also like to express our thanks for the expert technical assistance of Mr. James M. Byrne and the excellent secretarial assistance of Ms. Darlene Speltz.

This investigation was supported in part by research grants HL-19001 and HL-17430 from the U. S. Public Health Service, National Institutes of Health.

\section{REFERENCES}

1. Bowie, E. J. W., C. A. Owen, Jr., P. E. Zollman, J. H. Thompson, Jr., and D. N. Fass. 1973. Tests of hemostasis in swine: normal values and values in pigs affected with von Willebrand's disease. Am. J. Vet. Res. 34: 1405-1407.

2. French, J. E., M. A. Jennings, and H. W. Florey. 1965. Morphological studies on atherosclerosis in swine. Ann. N. Y. Acad. Sci. 127: 780-799.

3. Getty, R. 1965. The gross and microscopic occurrence and distribution of spontaneous atherosclerosis in the arteries of swine. In Comparative Atherosclerosis: The Morphology of Spontaneous and Induced Atherosclerotic Lesions in Animals and Its Relation to Human Disease. J. C. Roberts, Jr., and R. Straus, editors. Harper \& Row, Publishers, Inc., New York. 11-20.
4. Ratcliffe, H. L., H. Luginbühl, and L. Pivnik. 1970. Coronary, aortic and cerebral atherosclerosis in swine of 3 age-groups: implications. Bull. W.H.O. 42: 225-234.

5. Imai, H., and W. A. Thomas. 1968. Cerebral atherosclerosis in swine: role of necrosis in progression of dietinduced lesions from proliferative to atheromatous stage. Exp. Mol. Pathol. 8: 330-357.

6. Florentin, R. A., and S. C. Nam. 1968. Dietary-induced atherosclerosis in miniature swine. I. Gross and light microscopy observations: time of development and morphologic characteristics of lesions. Exp. Mol. Pathol. 8: 263-301.

7. Hill, E. G., W. D. Lundberg, and J. L. Titus. 1971. Experimental atherosclerosis in swine. II. Effects of methionine and menhaden oil on an atherogenic diet containing tallow and cholesterol. Mayo Clin. Proc. 46: 621-625.

8. Bowie, E. J. W., J. H. Thompson, Jr., P. Didisheim, and C. A. Owen, Jr. 1971. Mayo Clinic Laboratory Manual of Hemostasis. W. B. Saunders Company, Philadelphia. $186 \mathrm{pp}$.

9. Mertz, E. T. 1942. The anomaly of a normal Duke's and a very prolonged saline bleeding time in swine suffering from an inherited bleeding disease. Am. J. Physiol. 136: $360-362$.

10. Olson, J. D., W. J. Brockway, D. N. Fass, M. A. Magnuson, and E. J. W. Bowie. 1975. Evaluation of ristocetinWillebrand factor assay and ristocetin-induced platelet aggregation. Am. J. Clin. Pathol. 63: 210-218.

11. Laurell, C-B. 1966. Quantitative estimation of proteins by electrophoresis in Agarose gel containing antibodies. Anal. Biochem. 15: 45-52.

12. Zimmerman, T. S., O. D. Ratnoff, and A. E. Powell. 1971. Immunologic differentiation of classic hemophilia (factor VIII deficiency) and von Willebrand's disease: with observations on combined deficiencies of antihemophilic factor and proaccelerin (factor $V$ ) and on acquired circulating anticoagulant against antihemophilic factor. J. Clin. Invest. 50: 244-254.

13. Weiss, H. J., L. W. Hoyer, F. R. Rickles, A. Varma, and J. Rogers. 1973. Quantitative assay of a plasma factor deficient in von Willebrand's disease that is necessary for platelet aggregation. Relationship to factor VIII procoagulant activity and antigen content. J. Clin. Invest. 52: $2708-2716$.

14. Levine, J. B., and B. Zak. 1964. Automated determination of serum total cholesterol. Clin. Chim. Acta. 10: 381-384.

15. Block, W. D., K. J. Jarrett, Jr., and J. B. Levine. 1966. Use of a single color reagent to improve the automated determination of serum total cholesterol. In Technicon Symposia 1965: Automation in Analytical Chemistry. L. T. Skeggs, Jr., editor. Mediad, New York. 345-347.

16. Ellefson, R. D., and W. T. Caraway. 1976. Lipids and lipoproteins. In Fundamentals of Clinical Chemistry. N. W. Tietz, editor. W. B. Saunders Company, Philadelphia. 2nd edition. 474-541.

17. Kessler, G., and H. Lederer. 1966. Fluorometric measurement of triglycerides. In Technicon Symposia 1965: Automation in Analytical Chemistry. L. T. Skeggs, Jr., editor. Mediad, New York. 341-344.

18. Mitchell, J. R. A., and C. J. Schwartz. 1965. The morphology of arterial plaques. In Arterial Disease. F. A. Davis Company, Philadelphia. 15-49.

19. Holman, R. L., H. C. McGill, Jr., J. P. Strong, and J. C. Gerr. 1958. Technics for studying atherosclerotic lesions. Lab. Invest. 7: 42-47.

20. Mitchell, J. R. A., and C. J. Schwartz. 1965. The morphol- 
ogy of arterial plaques. In Arterial Disease. F. A. Davis Company, Philadelphia. 50-67.

21. Anderson, T. F. 1951. Techniques for the preservation of three-dimensional structure in preparing specimens for the electron microscope. Trans. N. Y. Acad. Sci. 13: 130-134.

22. Fass, D. N., W. J. Brockway, C. A. Owen, Jr., and E. J. W. Bowie. 1976. Factor VIII (Willebrand) antigen and ristocetin-Willebrand factor in pigs with von Willebrand's disease. Thromb. Res. 8: 319-327.

23. Booyse, F., A. Quarfoot, S. Bell, D. Fass, J. Lewis, and K. Mann. 1976. Properties of porcine von Willebrand aortic endothelial cells. Circ. Suppl. 54: II-120. (Abstr.)

24. Baumgartner, H. R., T. B. Tschopp, and D. Meyer. 1977. Shear rate dependence of platelet adhesion to collagenous surfaces in Willebrand factor-depleted blood. Thromb. Haemost. 38: 50. (Abstr.)

25. Bowie, E. J. W., and C. A. Owen, Jr. 1973. The value of measuring platelet "adhesiveness" in the diagnosis of bleeding diseases. Am. J. Clin. Pathol. 60: 302-308.

26. Weiss, H. J., T. B. Tschopp, and H. R. Baumgartner. 1975. Impaired interaction (adhesion-aggregation) of platelets with the subendothelium in storage-pool disease and after aspirin ingestion: a comparison with von Willebrand's disease. N. Engl. J. Med. 293: 619623.

27. Borchgrevink, C. F. 1961. Platelet adhesion in vivo in patients with bleeding disorders. Acta Med. Scand. 170: $231-243$.

28. Stemmerman, M. B., and R. Ross. 1972. Experimental arteriosclerosis. I. Fibrous plaque formation in primates, an electron microscope study. J. Exp. Med. 136: 769-789.

29. Ross, R., J. Glomset, B. Kariya, and L. Harker. 1974. A platelet-dependent serum factor that stimulates the proliferation of arterial smooth muscle cells in vitro. Proc. Natl. Acad. Sci. U. S. A. 71: 1207-1210.

30. Harker, L. A., R. Ross, S. J. Slichter, and C. R. Scott. 1976. Homocystine-induced arteriosclerosis. The role of endothelial cell injury and platelet response in its genesis. J. Clin. Invest. 58: 731-741.

31. Burns, E. R., R. J. Friedman, E. G. Puszkin, M. B. Stemmerman, and T. H. Spaet. 1976. The effects of dipyridamole and aspirin on arteriosclerotic plaque formation in rabbits. Circ. Suppl. 54: II-138. (Abstr.)

32. Moore, S., R. J. Friedman, D. P. Singal, J. Gauldie, and M. Blajchman. 1976. Inhibition of injury induced thromboatherosclerotic lesions by antiplatelet serum in rabbits. Thromb. Diath. Haemorrh. 35: 70-81.

33. Cohen, P., and H. L. McCombs. 1968. Platelets and atherogenesis. Part 2. Amelioration of cholesterol atherogenesis in rabbits with reduced platelet counts as the result of ${ }^{32} \mathrm{P}$ administration. J. Atheroscler. Res. 8: 389-398.

34. Cohen, P., and H. L. McCombs. 1967. Platelets and atherogenesis. I. Augmentation of cholesterol atherogenesis in the rabbit by a phlebotomy programme designed to induce thrombocytosis. Br. J. Exp. Pathol. 48: $346-356$.

35. Somer, J. B., G. Evans, and C. J. Schwartz. 1972. Influence of experimental aortic coarctation on the pattern of aortic Evans blue uptake in vivo. Atherosclerosis. 16: $127-133$.
36. Frost, H. 1970. Study of the pathogenesis of obliterating arterial disease by means of tarter electron microscope technique. In Platelets and the Vessel Wall-Fibrin Deposition; Symposium of the European Atherosclerosis Group, 15-17 June 1969. G. Schettler, editor. Georg Thieme Verlag, Stuttgart. 124.

37. Ross, R., and L. Harker. 1976. Hyperlipidemia and atherosclerosis: chronic hyperlipidemia initiates and maintains lesions by endothelial cell disquamation and lipid accumulation. Science (Wash. D. C.). 193: 10941100.

38. Sunaga, T., Y. Yamashita, F. Numan, and T. Shimamoto. 1970. Luminal surface of normal and atherosclerotic arteries observed by scanning electron microscope. Proceedings of the 3rd annual scanning electron microscope symposium. Chicago, Ill. 243-248.

39. Davies, P. F., M. A. Reidy, T. B. Goode, and D. E. Bowyer. 1976. Scanning electron microscopy in the evaluation of endothelial integrity of the fatty lesion in atherosclerosis. Atherosclerosis. 25: 125-130.

40. Lewis, J. C., and B. A. Kottke. 1977. Endothelial damage and thrombocyte adhesion in pigeon atherosclerosis. Science (Wash. D. C.). 196: 1007-1009.

41. Fry, D. L. 1969. Certain chemorheologic considerations regarding the blood vascular interface with particular reference to coronary artery disease. Circ. Suppl. 3940: IV-38-57.

42. Texon, M. 1960. The hemodynamic concept of atherosclerosis. Bull. N. Y. Acad. Med. 36: 263-274.

43. Glagov, S. 1973. Mechanical stresses on vessels and the non-uniform distribution of atherosclerosis. Med. Clin. North Am. 57: 63-77.

44. Wesolowski, S. A., C. C. Fries, A. M. Sabini, and P. N. Sawyer. 1965. The significance of turbulence in hemic systems and in the distribution of the atherosclerotic lesion. Surgery (St. Louis). 57: 155-161.

45. Mustard, J. F. 1975. Platelets, drugs and thrombosis, the problem. In Platelets, Drugs and Thrombosis; Proceedings of a Symposium held at McMaster University, Hamilton, Ontario, 16-18 October 1972. J. Hirsh, J. F Cade, A. S. Gallus, and E. Schonbaum, editors. S. Karger, Basel. 322 pp.

46. Fry, G. L., R. D. Maca, and J. C. Hoak. 1976. Enhancement of endothelial contiguity by human platelets. Clin. Res. 24: 570. (Abstr.)

47. Gimbrone, M. A., R. H. Aster, R. S. Cotran, J. Corkery, J. H. Jandl, and J. Folkman. 1969. Preservation of vascular integrity in organs perfused in vitro with a platelet-rich medium. Nature (Lond.). 222: 33-36.

48. Wojcik, J. D., D. L. Van Horn, A. J. Webber, and S. A. Johnson. 1969. Mechanism whereby platelets support the endothelium. Transfusion (Phila.). 9: 324-335.

49. Roskam, J. 1964. Du rôle de la paroi vasculaire dans l'hémostase spontanée et al pathogénie des états hémorragiques. Thromb. Diath. Haemorrh. 12: 338-352.

50. Fass, D. N., P. Didisheim, J. C. Lewis, and E. F. Grabowski. 1976. Adhesion of porcine von Willebrand (VWD) platelets. Circ. Suppl. 54: II-116. (Abstr.)

51. Silwer, J., S. Cronberg, and I. M. Nilsson. 1966. Occurrence of arteriosclerosis in von Willebrand's disease. Acta Med. Scand. 180: 475-484. 